\title{
Transubstanciação simbólica do uniforme de trabalho em signo de prestígio'
}

\author{
Rita de Cássia Pereira Farias ${ }^{2}$
}

RESUMO: $\bigcirc$ artigo analisa os usos sociais e significados simbólicos presentes no uniforme de trabalho usado pelos funcionários da Usiminas - siderúrgica sediada em lpatinga (MG). Esse uniforme é um dos maiores símbolos de prestígio na região, vestido por todos os funcionários, independentemente do nível hierárquico ou gênero (sob justificativa de nivelar todos, até mesmo o presidente da companhia o usa). A realidade em estudo revela um paradoxo entre a necessidade de igualar, pela roupa, os trabalhadores e a hierarquia na empresa, que aponta para diferenças. Para desvelar o universo simbólico ao qual o uniforme se liga, a análise articula antropologia simbólica, cultura material e história social, recuperando o percurso histórico quanto à adoção dos uniformes nas fábricas brasileiras, bem como o contexto em que a Usiminas foi implantada. No processo de disputas simbólicas no espaço urbano, o uniforme foi útil para moldar comportamentos e "civilizar" os operários. Apesar do controle exercido pelo uniforme, os privilégios conseguidos por meio dele transformam-no em símbolo de status. Os dados evidenciam que, mais que um material inerte, destinado a proteger os trabalhadores, o uniforme materializa relações de gênero e de classe, e adquire uma vida social essencialmente dinâmica, "impregnada" de memórias, sonhos e conquistas, além de ser marcado por perseguições, demissões, medo e dor.

PALAVRAS-CHAVE: Uniforme de trabalho. Investimento simbólico. Usos sociais. Usiminas. lpatinga.

ABSTRACT: The article examines the social uses and symbolic meanings which are present in the working uniform adopted by Usiminas, a large steel company located in Ipatinga (MG). This uniform is one of the greatest symbols of prestige in the region, since all the employees wear it, regardless of hierarchy level or gender (under a discourse of equality, it is worn even by the president of the company). The reality under investigation reveals a paradox between the need to equalize the workers by the garment and the company hierarchy, which may imply differences. To unveil the symbolic universe to which the uniform is connected, the analysis articulated symbolic anthropology, material culture and social history, retrieving the historical background regarding the adoption of uniforms in Brazilian factories as well as the context in which Usiminas was implanted. In the process of symbolic disputes in urban spaces, the uniform
1. O artigo é uma compilação da minha tese de doutorado Entre a igualdade $e$ a distinção: a trama social de uma grande empresa corporificada no uniforme de trabalho, financiada pela Capes, defendida em março de 2010, no departamento de Antropologia da Unicamp, sob orientação da professora Heloisa Pontes.

2. Doutora em Antropologia Social pela Unicamp, professora do curso de Economia Doméstica da Universidade Federal de Viçosa. E-mail: $<$ farias.rcp@gmail.com> 
was useful to shape behaviors and "civilize" the workers. However, in spite of the control which is possible through the uniform, the access to many privileges have contributed to transform it into a status symbol. The data show that, rather than an inert material to protect workers, the uniform materializes gender and class relations, has an essentially dynamic social life, "impregnated" by memories, dreams and accomplishments, besides being marked by persecution, layoffs, fear and pain.

KEYWORDS: Working uniform. Symbolic investment. Social use. Usiminas. Ipatinga.

Introdução

artigo consta de uma análise sobre os usos sociais e significados simbólicos presentes no uniforme de trabalho adotado na siderúrgica Usiminas, sediada em lpatinga (MG). Esse uniforme é um dos maiores símbolos de prestígio na região, já que todos os funcionários o vestem, independentemente do nível hierárquico ou gênero, até mesmo o presidente da companhia o usa, sob a justificativa de "nivelar"-se aos trabalhadores, tornando todos "iguais", "sem distinção ou discriminação". Entretanto, a hierarquia na empresa aponta para diferenças no salário, nas condições de trabalho e nas relações humanas. Assim, procurei verificar como se concilia o paradoxo entre a igualdade e a hierarquia, além de buscar apreender as forças que sustentam o discurso igualitário.

Para entender o paradoxo entre a uniformização e a hierarquia na empresa no contexto da dinâmica da sociedade de lpatinga, fiz uma pesquisa etnográfica. Recorrendo à observação participante, residi por quatro meses na cidade juntamente com meus dois filhos, que estudaram em uma escola do bairro, associei-me a um clube onde fiz aulas de hidroginástica e meu filho frequentou uma escolinha de futebol. Além da pesquisa etnográfica, busquei compreender, na história, os aspectos ligados à adoção de uniformes pelas empresas brasileiras, bem como a implantação da Usiminas em lpatinga.

Logo nos primeiros dias em que estava residindo em lpatinga e realizando a pesquisa de campo, a esposa de um engenheiro da Usiminas foi a primeira pessoa a quem falei de minha pesquisa e ela logo afirmou: "Posso the adiantar que os funcionários da Usiminas têm o maior orgulho dos uniformes, é uma coisa que é transmitida de pai para filho. Eles usam muito a expressão 'vestir a camisa da empresa!!" Diante desse depoimento e de outros que apontavam para o uniforme da Usiminas como um dos maiores símbolos de status da região, procurei respostas para minhas indagações, buscando entender, no contexto sociocultural de lpatinga, o sentido atribuído aos uniformes: Como se constrói esse orgulho? $\bigcirc$ que faz esse tipo de uniformização funcionar em lpatinga como um símbolo de status? Que significados podem ser atribuídos ao fato de os dirigentes e os operários usarem o mesmo uniforme?

Embora o uniforme da Usiminas seja um símbolo de prestígio, a adoção de uniformes pelas empresas brasileiras está ligada ao signo da submissão. Ou seja, a uniformização dos trabalhadores da indústria brasileira está atada à ideologia do "soldado operário", no contexto da Segunda Guerra Mundial, 
quando Getúlio Vargas fez um acordo com os Estados Unidos para a construção de uma base aérea em Natal, cuja posição estratégica era favorável, na guerra, ao pouso e abastecimento dos aviões dos países aliados aos Estados Unidos. Em troca, o Brasil recebeu financiamento para a implantação da Companhia Siderúrgica Nacional (CSN), visando a promover a industrialização e o progresso do país.

Em meio à euforia dos operários que trabalhavam na construção da CSN, em primeiro de maio de 1942, Getúlio Vargas lançou a Campanha "soldados operários", exigindo dos trabalhadores todo o esforço para promover o país em tempos de guerra. Assim, com seus uniformes do tipo macacão, os trabalhadores desfilaram perante Vargas assumindo o compromisso de lutar na "batalha da produção"3.

Vargas procurou construir um operário dócil e subordinado aos interesses do Estado, cassando, prendendo e exilando aqueles que fossem contrários à sua política ditatorial. No processo de construção do operário apolítico, foi fundamental o papel do Senai no atendimento aos interesses dos industriais que aderiram ao modelo de "soldado operário" e uniformizaram seus trabalhadores ${ }^{4}$.

O domínio dos ideais de Vargas se estendeu até o final da década de 1980. Assim, na década de 1990, diante da abertura da economia e da concorrência globalizada, os uniformes militarizados perderam espaço, e as empresas investiram em uniformes assinados por estilistas renomados, visando a agregar valor à imagem empresarial, imitando a iniciativa da empresa aérea Air France, que, a partir de 1946, adotou uniformes elaborados por estilistas. Em 2000 houve uma tendência da informalidade dos uniformes. Até mesmo setores tradicionais como os Correios e a Polícia aderiram aos uniformes em versão ciclista. ${ }^{5}$

Já a implantação da Usiminas em lpatinga, cujas obras foram iniciadas em 1958 (e a produção industrial em 1962), deu-se no governo de Juscelino Kubitschek, como parte do seu Plano de Metas. A meta "cinquenta anos em cinco" visava a acelerar o desenvolvimento econômico do país através de grandes investimentos na indústria nacional, especialmente a siderúrgica. A Usiminas foi implantada mediante um acordo com o Japão, país que detinha a tecnologia de ponta no setor siderúrgico. Assim, diversos japoneses vieram ao Brasil para instalar a Usina, e vários brasileiros participaram de missões de treinamento no Japão.

Diversos conflitos foram gerados ao gerir uma população composta por cerca de doze mil trabalhadores em um vilarejo destituído de infraestrutura. Dentre as estratégias empregadas na "formatação" de um operário apolítico, o uniforme teve papel central, principalmente por terem sido empregadas diversas estratégias para que, diante do restante da população que acorreu a lpatinga, essa vestimenta constituísse um instrumento de prestígio e fator de vantagem. Os benefícios que proporcionava motivavam seu uso em tempo integral. Entretanto, ao mesmo tempo em que conferia prestígio e vantagens aos trabalhadores, era um instrumento coercitivo, que motivava denúncias de desvio na conduta esperada pela empresa.
3. Cf. Regina da L. Moreira (2005, p. 59).

4. Ver Rita de C. Farias (2010).

5. Adilson Almeida (1998) menciona terem os uniformes funções pragmáticas diacríticas e simbólicas. As funções pragmáticas referem-se à aplicação prática do uniforme, devido às suas características estruturais (materiais e métodos de confecção, cores e modelos). As funções diacríticas estão ligadas às propriedades distintivas dos uniformes, que possibilitam visualizar posições hierárquicas, mediante a diferenciação nos modelos internos, uso de emblemas e sinais. Já as funções simbólicas dizem respeito aos significados, valores, princípios, expectativas, produção de sentido e representações que recaem sobre os usuários dos uniformes. Embora essas funções sejam apresentadas separadamente (para efeitos didáticos), na prática, elas se sobrepõem e mesclam-se. De uma maneira geral, entendo que a uniformização serve aos seguintes propósitos: 1 . Proteção e segurança do usuário; 2. Economia, pois evita que o usuário use suas próprias roupas; 3 . Higiene; 4 . Comunicação (permite divulgar uma imagem empresarial); 5. Demonstração de pudor; 6. Estabelecimento de disciplina, ordem e limites (possibilita controlar as emoções e o comportamento); 7. Demonstração de uma posição social (evidencia o status e diferencia as classes; 8. Comunicação de identidade e pertencimento; 9. Sinalização de exclusão (presidiários); e, finalmente, 10 . Destaque de ideais revolucionários e igualitários. 
6. Cf. Usiminas (1987, p 21).

7. Ver Usiminas Jornal, maio 2004.

8. Cf. Paulo Roberto de Souza (2007, p. 38) recrutamento dos trabalhadores: expectativas, decepções e conflitos

Quando a Usiminas foi implantada em 1958, a Rádio Nacional divulgou em todo o país a notícia de que o progresso havia chegado ao leste mineiro, onde seria construída uma grande e moderna siderúrgica.

$\bigcirc$ anúncio da instalação da siderúrgica revestiu-se de grande simbolismo e expectativas quanto ao desenvolvimento industrial. As pessoas que não conheciam a região imaginaram uma cidade grande e desenvolvida, capaz de proporcionar melhores oportunidades de vida. Já as pessoas da região, ao ouvir falar e ao imaginar a chegada do tão falado progresso, fomentavam grandes expectativas. Em função das esperanças daqueles que se deslocaram em busca de trabalho, criou-se no imaginário popular a ideia de que na região havia muito dinheiro. Assim, tornou-se comum se referir a essa localidade como Eldorado, Canaã do Aço ou Terra Prometida. Mais tarde, por razões políticas, essas terminologias foram substituídas por Vale do Aço.

Para a construção da siderúrgica, o vilarejo de lpatinga - então distrito de Coronel Fabriciano -, que abrigava aproximadamente 300 moradores, recebeu uma população estimada em 12 mil pessoas. Contrariamente ao progresso que eles imaginavam, no lugar não havia infraestrutura, nem casas para morar, água potável, ou sequer onde comprar gêneros alimentícios ou materiais de construção. O vilarejo contava apenas com uma estação de trem e a rua "do Comércio", onde havia um bar, duas mercearias, uma farmácia e duas lojas de tecidos. Para se abrigarem, as pessoas que aí chegaram, utilizando a madeira que embalava o maquinário vindo do Japão, construíram barracos cuja cobertura eram sacos de cimento, vazios, que sobravam da construção da Usiminas.

Na ocasião de sua primeira visita a lpatinga, em 1958, ao comentar a impressão que teve do lugarejo, o engenheiro japonês Hirokasu Kato ressaltou que "Ipatinga parecia ser um pedaço de terra isolada do resto do mundo"6. De modo semelhante, Rinaldo Campos, presidente da Usiminas, afirmou que "Ipatinga era a imagem da desesperança quando ali a Usiminas chegou"7.

Em função dos problemas estruturais e sociais do vilarejo, os trabalhadores que sonhavam encontrar uma cidade bem estruturada ficaram desapontados com a realidade com a qual se deparavam. Voltar para a cidade de origem denotaria fracasso, afinal, eles haviam depositado muitas expectativas em torno desse projeto de vida que, no entanto, não foram aniquiladas, embora o impacto tenha causado estranheza e decepção. "Os desafios, que se formariam diante das dificuldades apresentadas pelo cotidiano, despertariam nesses forasteiros uma força interior jamais imaginada; e é dessa força que eles tirariam a energia necessária à construção do sonho." ${ }^{\text {. }}$ Afinal, se o Eldorado não existia, ele poderia vir a existir. Essas eram as expectativas.

Como a siderurgia era uma atividade relativamente nova no país, e a Usiminas não tinha nada a oferecer aos trabalhadores além do salário, o povoado foi visto como local de aventureiros. Além das dificuldades quanto à infraestrutura, a população de lpatinga era bastante heterogênea, sem coesão e destituída de 
princípios comuns. Os constantes crimes que ocorriam no vilarejo causavam medo entre os habitantes, como menciona Paulo Roberto de Souza:

Muitos moradores consideravam lpatinga uma curva de rio, no qual era depositado todo o rejeito que a água consegue carregar [...]. Um ambiente que, segundo parte da população, abarcou todo tipo de pessoas desprovidas de porvir, muitas delas rejeitadas em suas cidades de origem [...] e que encontraram em lpatinga uma oportunidade para tentar refazer a vida, ou iniciá-la de acordo com a necessidade do momento?.

Além dos problemas estruturais e sociais, também era problemática a gerência de milhares de trabalhadores no espaço fabril. $\bigcirc$ trabalho na siderúrgica era realizado em condições insalubres, sob alta temperatura (em torno de $1600^{\circ}$ ) e inalação de gases tóxicos. Soma-se a isso a distância dos familiares. Diante de tantos problemas, eram comuns casos de loucura, que suscitavam preocupação nos dirigentes da empresa, como afirmou Amaro Lanari, ex-presidente da Usiminas ${ }^{10}$.

Como eram comuns furtos na empresa, policiais rudes inspecionavam a saída dos trabalhadores e, visando a assegurar a ordem, recorriam a mecanismos disciplinares violentos, dentro e fora da fábrica, gerando muita revolta na população.

acúmulo de problemas sociais e profissionais, aliado às práticas intimidatórias e violentas pela polícia, gerava insatisfações e revoltas nos trabalhadores. Diante dessa situação conflitante, a tentativa de controle extrapolou - limite suportável levando os operários a reagir. Os policiais que faziam a guarda da Usiminas, em sua tentativa de dominar a situação, usaram de metralhadoras, o que desencadeou, em 7 de outubro de 1963, um conflito - $\bigcirc$ massacre de lpatinga - que resultou em dezenas de mortos e feridos. Por ser uma mancha no passado da empresa, a Usiminas procurou apagar todos os vestígios desse incidente, ocultando o número real de mortos. Além disso, impôs sobre ele um silêncio: o massacre não aparece nas páginas de sua história oficial. $\bigcirc$ sigilo forçado gerou um tabu em torno da tragédia: todos tinham medo de tocar nesse assunto proibido e serem punidos ${ }^{11}$.

Após o massacre, a Usiminas adotou uma política de melhoria no relacionamento dos chefes com os trabalhadores, elevou os salários e acelerou a construção de seus bairros residenciais, seguindo o modelo company town, que foi muito útil na implantação e consolidação das medidas administrativas pautadas na vigilância e no controle.

Os bairros construídos pela Usiminas refletiam a hierarquia na empresa. Havia bairros específicos para dirigentes, engenheiros e operários. Embora as casas fossem diferenciadas, eles foram dotados de excelente infraestrutura, com diversas praças, clubes e centro comercial, o que contrastava com a realidade dos demais moradores, que viviam em barracos. Assim, a entrega das casas constituía um rito de passagem, que implicava a imposição de uma nova moralidade e a "formatação" de um operário civilizado e grato à empresa pelas benesses que ela the concedia. Dotar seus bairros de centro comercial era uma forma de afastar os trabalhadores do centro da cidade, onde havia a zona
9. Idem, p. 54

10. Cf. Usiminas (1987, p. 15).

11. Ver Rita de Cássia P. Farias (2010); Marilene Tuler (2007). 
boêmia e de prostituição, e impor uma moralidade ao trabalhador, atrelada à imagem do pai de família responsável e dedicado.

processo de transubstanciação simbólica do uniforme em signo de prestígio

Na década de 1970, a Usiminas adotou uniformes que davam visibilidade aos trabalhadores, facilitando sua identificação ao usufruírem benfeitorias no comércio. Mediante um acordo com a Usiminas, as novas lojas ofereciam produtos que não se encontravam no comércio tradicional. Além disso, a siderúrgica fornecia aos trabalhadores e seus familiares a vantagem de comprar a crédito, tendo o valor descontado em folha de pagamento. Para desfrutar das vantagens que o comércio oferecia, bastava estar vestido com o uniforme da Usiminas. A interdição de acesso ao crédito àqueles que não estavam inseridos na siderúrgica contribuiu para consolidar o orgulho de vestir o uniforme da Usiminas, motivando o seu uso também antes e após o trabalho.

Como proporcionava prestígio na região, o uniforme tornou-se objeto de desejo dos habitantes do Vale do Aço. Em uma conversa informal, ao comentar o status conferido pelo uniforme, Marília Lima (35 anos) me relatou que, ao cursar o segundo grau e estagiar na Usiminas (entre 1992 e 1993), sentia muito orgulho em ir para o colégio usando o uniforme da empresa. Inclusive, quando tinha tempo de passar em casa após o estágio, ela tomava banho e vestia outro uniforme da Usiminas para ir ao colégio. Em suas palavras, isso acontecia porque "Era uma honra estar de uniforme e ouvir meus colegas me perguntar se eu estava estagiando na Usiminas!"

Ao se reportar aos tempos áureos da Usiminas, alguns estudantes de Ipatinga ressaltam o orgulho dos trabalhadores em usar o uniforme. Como destaca Louiza Gabrielle, "Assim como usar determinadas marcas pode indicar a condição social e conferir prestígio ao usuário, no início da história de lpatinga, usar o uniforme da Usiminas significava mais que estar empregado". Michelly Toledo ressalta que, quando estavam vestidos com o uniforme com a marca registrada da Usiminas, os trabalhadores se sentiam como se estivessem vestindo uma roupa elegante, pois "um simples uniforme era um grande símbolo de status e de elite". Segundo a estudante Isabella Rodrigues, sem o uniforme, eles eram vistos como "cidadãos comuns; já com eles, os trabalhadores eram investidos da autoridade que suas funções thes concediam", podendo demonstrar seu status perante a sociedade. Maria Leandra Souza, estudante do Ensino Médio, comentou que o trabalhador uniformizado se sentia poderoso e orgulhoso "como se estivesse vestindo uma roupa de gala [...] Ao sair do serviço, nem trocava de roupa para ser mais bem atendido". $\bigcirc$ estudante Cliton Medina também mencionou que, até em restaurantes e lugares públicos, os trabalhadores uniformizados eram tratados melhor que as pessoas que estavam bem vestidas.

Além do prestígio no comércio, o uniforme possibilitava a identificação do trabalhador em caso de inspeção no trânsito. Um técnico da siderúrgica 
mencionou que, devido ao conceito da Usiminas na região, o selo de identificação da empresa usado no carro liberava os trabalhadores de uma blitz da polícia rodoviária, o que levava os funcionários a valorizar ainda mais a relação de trabalho ${ }^{12}$.

Devido ao alto investimento da Usiminas na moralização dos trabalhadores, um engenheiro aposentado mencionou, em uma entrevista, que "se você se envolver em alguma dificuldade, como uma batida de carro, quem está com uniforme da Usiminas... se é que vai levar alguma vantagem é o que está com o uniforme da Usiminas". Ao conferir visibilidade a características sociais, habilidades, atitudes e hábitos valorizados na sociedade local, colocando os trabalhadores da Usiminas em vantagem, o uniforme acabou configurando-se não apenas como roupa de trabalho, mas de exibição. Vestir o uniforme em tempo integral evidencia que sua função não é apenas proteger o trabalhador, mas conferir destaque e prestígio, já que denota a participação e inserção na empresa de maior renome e tradição na cidade.

Na formatação do "novo trabalhador", a Usiminas impôs uma moralidade atada à figura do bom pai de família, motivando o casamento entre os solteiros. Afinal, ser provedor familiar aumentaria a dependência do trabalhador para com a empresa. Com esse intuito, a empresa promovia bailes e enviava ônibus para buscar as mulheres da região "para interagir com os trabalhadores", como afirmou Paulo, metalúrgico aposentado. $\bigcirc$ uniforme cinza indicava os "bons partidos para casamento", pois sinalizava que as moças se casariam com trabalhadores de uma empresa séria, que pagava bem e não atrasava o pagamento, além de oferecer a segurança de fazer compras na cooperativa Consul, atendimento no Hospital Márcio Cunha e instrução formal no Colégio São Francisco Xavier, todos pertencentes à Usiminas. Soma-se a isso a vantagem de morar em uma casa boa e bem localizada. Assim, quando uma moça estava de casamento marcado com um operário da Usiminas, as pessoas comentavam "fulana vai se casar com sicrano, funcionário da Usiminas, ela vai morar em casa de laje, ela vai ficar rica!" Morar em "casa de laje" era um grande privilégio, diante da carência das famílias que moravam em barracos.

Uma forma de ressaltar a importância do uniforme na valorização do trabalhador e sua família era quando morria um funcionário da Usiminas ou um de seus parentes. Os colegas de trabalho compareciam no velório uniformizados, como forma de reforçar a identidade empresarial e a solidariedade entre os membros da equipe. Essa iniciativa era vista pela família do finado como motivo de orgulho, pois demonstrava que o trabalhador (ou familiar) era valorizado pela empresa. Na visão de Alair, esposa de um engenheiro da Usiminas, é "como se representasse que na dor eles estavam unidos no mesmo traje". Um engenheiro aposentado há quinze anos pela Usiminas, ressaltou o valor dado pela sociedade à presença de funcionários uniformizados nos velórios:

Ir a um funeral, por exemplo, impressiona muito! [...] Se tiver um funeral, ela [a Usiminas] manda representantes. Então, a família se sente orgulhosa de ver [os funcionários da Usiminas] com os uniformes. [Os presentes comentam:] "aqueles ali são todos representantes da Usiminas." E não é só aqui em lpatinga não. Se morre um funcionário ou um parente do
12. Em depoimento a Daniel Pardini e coautores (2008, p. 59). 
13. Cf. Pierre Bourdieu e Yvette Delsaut (2006, p. 152). funcionário fora daqui, os daqui vão uniformizados. E isso é muito marcante. A família se sente orgulhosa, né? [Eles pensam assim:] "Meu pai era importante para a Usiminas".

Devido ao status conferido pelo uniforme, os trabalhadores das oficinas da Usiminas que trabalham com graxa, por sujarem muito suas roupas durante a realização das tarefas, ao encerrarem o serviço, tomavam banho e saíam da empresa limpos e refeitos. Entretanto, ao invés de vestirem uma roupa de uso pessoal, já que estariam deixando a fábrica e indo ao comércio, ao clube esportivo, à sua casa ou mesmo caminhar (como é comum em lpatinga, após um dia de trabalhol, após o banho, vestiam outro uniforme, limpo, para usufruir do prestígio e vantagens que ele proporcionava. Afinal, para que o discurso quanto ao orgulho do uso do uniforme surtisse pleno efeito entre os operários e a Usiminas mantivesse sua imagem de "empresa séria", que valoriza seus funcionários, não seria conveniente que os trabalhadores carregassem em seus corpos a evidência do trabalho braçal, pesado e sujo.

Diante da projeção da Usiminas no cenário nacional e internacional, dos rituais ricamente elaborados que ela promove, dos prêmios que recebe, e, por ser uma das marcas mais valorizadas do país, usar o uniforme da empresa tem valor e confere prestígio local semelhante ao proporcionado por uma roupa de grife famosa. Entretanto, as roupas de grife, por serem projetadas para durar apenas uma estação, logo se tornam démodés. Já o uniforme da Usiminas, que pode durar uma vida e atravessar gerações, permite que o capital simbolizado pelo nome da empresa se converta em prestígio para os usuários, tornando-se símbolo de distinção que expressa a tradição da empresa, seu poder em sobreviver no tempo e acumular forças, mediante estratégias que escapam aos domínios das leis da economia.

Assim como uma roupa assinada por um grande costureiro é um objeto simbólico capaz "de conferir raridade pela simples imposição da grife"13, o uniforme, embora pareça uma roupa comum, pode ser visto como um objeto simbólico raro, pois é o único que traz a marca Usiminas - que em 2008 estava entre as dez marcas mais valiosas do país. Como pondera a estudante Jéssica Brant: "Talvez o impacto não esteja no uniforme, mas no peso do nome que ele carrega". Afinal, o que permite a valorização dessa vestimenta não se trata somente de cifras de produção da empresa e sua estratégia de comercialização, mas do capital simbólico acumulado, que age sobre o uniforme e transfere, como em um passe de magia, seu poder e sua glória.

Ao vestir o uniforme, os trabalhadores tiveram oportunidade de deixar sua condição de rebaixamento social e adquirir um novo status social e prestígio. Como aconteceu com a família do funcionário Cléber:

Meu pai veio de Caratinga para cá da roça, da lavoura, sem nada para trabalhar em uma empreiteira. As coisas eram muito difíceis. Morávamos em um cortiço de dois cômodos, eu, meu irmão, meu pai e minha mãe. Minha mãe lavava roupa para fora. No dia em que meu pai colocou o uniforme da Usiminas, em 1976, ele chegou em casa e disse que as coisas iriam melhorar. Ele estava há quatro anos em lpatinga. A partir do momento em que ele colocou aquele uniforme, a vida começou a mudar. Ele usava essa expressão: "Agora as coi- 
sas vão mudar!" Em minha memória, usar o uniforme estava ligado a uma mudança de vida e foi o que aconteceu. Na época ele comprou lote, construiu a casa, comprou carro. Para nós que estávamos acostumados com aquela pobreza, a nossa melhora de vida estava vinculada àquele uniforme que meu pai estava usando.

Para a família de operários que chegaram a lpatinga em uma condição miserável, vestir o uniforme da Usiminas e fazer parte do quadro de funcionários era uma alegria e uma honra. Joelma, 32 anos, graduada em Letras, filha de Antônio, aposentado pela Usiminas, lembra com empolgação a comida que era servida aos trabalhadores, mas que eles levavam para casa para a alegria dos filhos. Até ficar doente - para ser internado no Hospital Marcio Cunha - era motivo de alegria:

$\bigcirc$ uniforme da Usiminas lembra-me ascensão social. Sou filha de mecânico industrial da Usiminas. A participação do meu pai na Usiminas me dava o direito de associar ao clube mais frequentado da cidade (Usipa) e tomar banho de piscina todos os domingos. Ah! Podia até ficar doente só para consultar no hospital de primeiro mundo (o Márcio Cunha). Este uniforme também tinha cheiro e sabor. Todos os dias eu esperava ansiosa pelo delicioso "bandejão" (marmitex) que meu pai trazia no final do trabalho. Posso até hoje sentir o cheiro maravilhoso do feijão, que era tão diferente! E aquela sacolinha branca cheia de lanche! Laranja, maçã, iogurte, pão com salame... Que saudades!!!! Sinto até hoje o gosto em minha boca. E tem mais! Dia de promoção ou de festa para as famílias. Lembro-me dos jantares e churrasco fartos. Meu Deus, que comida!

Ao rememorar os acontecimentos importantes da sua vida, marcados pelo uniforme, Alair, esposa de um engenheiro da Usiminas, mencionou a enfermidade e a morte do seu irmão.

$\bigcirc$ fato mais marcante na minha vida foi ver o meu irmão doente, em fase terminal de câncer, no seu último mês de vida, em meio a tantas dores e sofrimento, ainda fazia questão de vestir o uniforme e ir para a Usina. Vestir o uniforme para ele representava força, coragem e vontade de vencer. Quando faleceu, todos diziam que ele deveria ser enterrado com o uniforme da Usina. Era a sua identidade, a roupa com a qual ele permaneceu por maior tempo de sua vida. E ele a vestia por amor. Jamais o vi reclamar de vestir este uniforme.

Por participar de acontecimentos importantes na vida dos trabalhadores e de suas famílias, marcando trajetórias e identidades, o uniforme pode ser visto como um "objeto biográfico"14. Por isso, é comum o trabalhador se aposentar e guardar por longos anos o uniforme, como Antônio, que havia trabalhado nos tempos áureos da Usiminas e, estando aposentado há dezessete anos, de vez em quando vestia seu uniforme, que guardava com muito orgulho. Joelma, sua filha, disse que amava quando via seu pai com o uniforme, pois tinha a impressão de que ele era uma pessoa muito importante. Em outubro de 2009, Antônio faleceu, e seu uniforme continuou sendo guardado com carinho pela filha. Se antes o uniforme representava a empresa para o pai, hoje ele representa o pai para a filha. Na Figura 1, Joelma mostra a camisa do uniforme.
14. Cf. Ecléia Bosi (1994, p. 441).

Annals of Museu Paulista. v. 18. n.2. July.-Dec. 2010. 


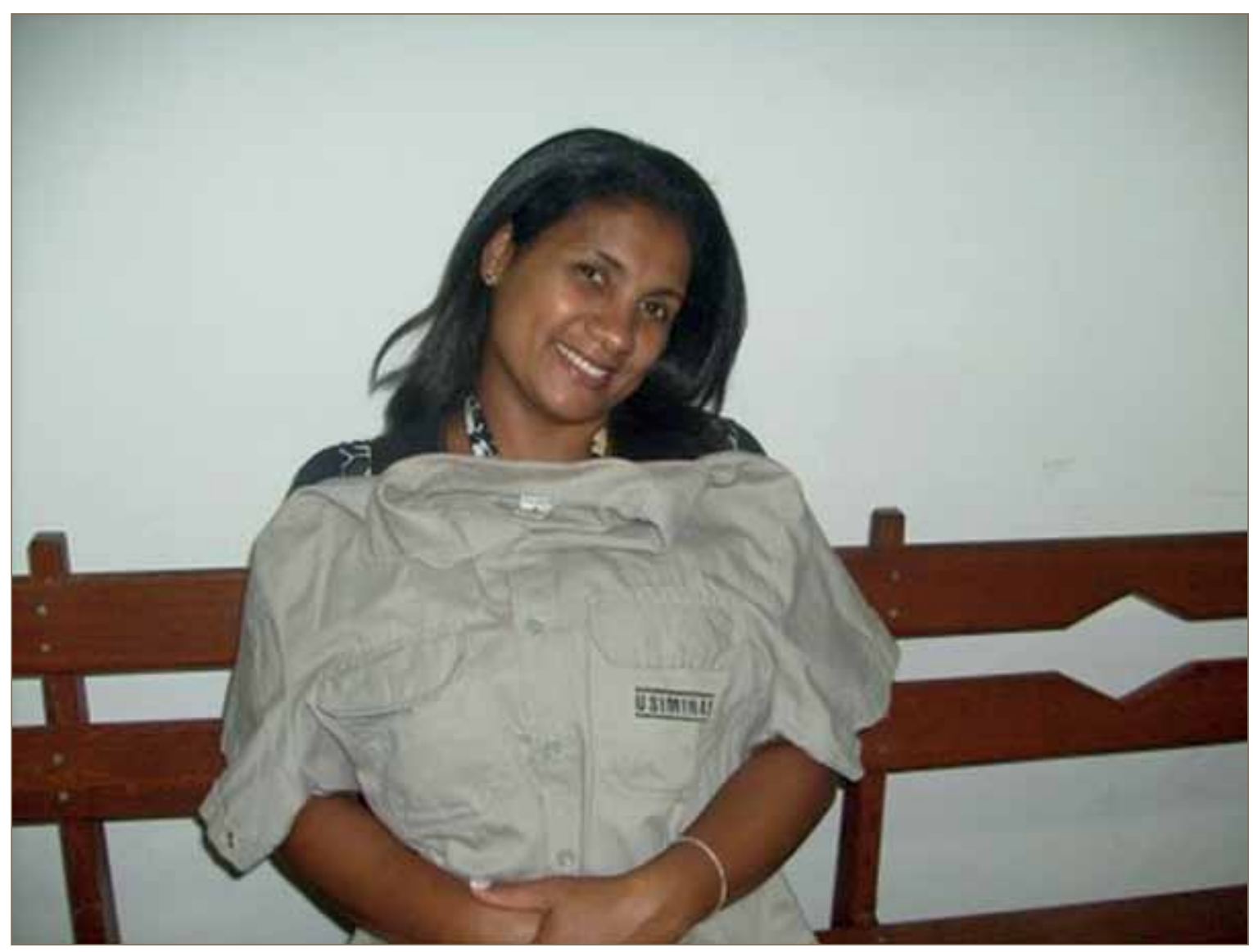

Figura 1 - Joelma com o uniforme do pai falecido, 2009. Fotografia de Rita Farias.

15. Cf. Peter Stallybrass (2004, p. 34).

16. Idem, p. 13
Essas evidências confirmam que a roupa assume uma característica quase mágica. Ela "pode efetuar as conexões do amor através das fronteiras da ausência, da morte, porque a roupa é capaz de carregar o corpo ausente, a memória, a genealogia, bem como o valor material litera|"15. Embora Antônio não esteja mais presente, Joelma conserva o uniforme do seu pai com os puídos e marcas de suor deixadas pelo tempo, juntamente com as memórias da família, especialmente dos lanches saborosos que ele levava pra casa. Como menciona Stallybrass: "A magia da roupa está no fato de que ela nos recebe: recebe nosso cheiro, nosso suor; recebe até mesmo nossa forma. E quando nossos pais, os nossos amigos e os nossos amantes morrem, as roupas ainda ficam lá, penduradas em seus armários, sustentando seus gestos ao mesmo tempo confortadores e aterradores, tocando os vivos com os mortos" 16 .

Devido ao simbolismo nele presente, ao longo da pesquisa o uniforme revelou-se um objeto muito enigmático, com diversos significados (e até sabor). Para as famílias, a entrada de um parente na empresa representava a aquisição de maior status na vizinhança e na comunidade, conferindo dignidade ao usuário. 
Assim, os pais tinham orgulho de dizer aos amigos: "meu filho é funcionário da Usiminas". Afinal, em lpatinga, o uniforme era um mecanismo de distinção social altamente eficaz e facilmente inteligível.

Embora a Usiminas seja uma empresa renomada, o uniforme não seria motivo de orgulho, se o investimento no processo de consagração do nome da empresa não fosse alto, além de uma demonstração de "valorização" dos funcionários. Mediante estratégias múltiplas, o uniforme cinza da Usiminas transmutava-se em signo de distinção e status.

Mudanças no comportamento e resgate da dignidade pelo uso do uniforme

$\bigcirc$ uniforme é um potente aliado na moldagem de comportamentos ${ }^{17}$. Ao vestir o uniforme, os trabalhadores incorporam uma persona ${ }^{18}$ que os move a agir conforme expectativas sociais, com atuação pautada no comprometimento corporativo. Como menciona Sebastião Patrício, 65 anos, engenheiro aposentado pela Usiminas: "Usando o uniforme, eu me sinto como que reafirmando um compromisso com a empresa. Sinto-me vinculado às normas da empresa". A extensão do uso do uniforme fora do recinto da fábrica leva o trabalhador a manter, em sua vivência social e familiar, o ideal de comportamento, indicando que está à disposição da empresa, como confirmou um engenheiro aposentado pela Usiminas: "Às vezes, era normal a gente ter que ir à Usina fora de hora. Mesmo que seja coisa rápida, tem que colocar o uniforme. Depois daí a gente até vai pra outro lugar, não tem importância, mas para entrar lá dentro tem que ser de uniforme. A gente se sente mal se for sem uniforme. É como a sensação de entrar de bermuda dentro da igreja".

$\bigcirc$ uniforme é significativo, especialmente para aqueles que estão ingressando no primeiro emprego, pois se sentem "mais responsáveis", "mais homens", "mais maduros", como ressaltou Rodrigo, que usou o uniforme durante seu estágio universitário. Como seu pai trabalhava na empresa há três décadas, vestir o uniforme the conferia a sensação de assumir o papel de seu pai como provedor, homem sério e responsável. $\bigcirc$ uso de um mesmo uniforme permitia aproximar a carreira de pai e filho, mesmo que no curto período do estágio.

Sebastião Patrício, engenheiro aposentado pela Usiminas, e sua esposa Noeme me disseram que, quando seu filho, que era "roqueiro, cabeludo e gostava de usar calças rasgadas", foi admitido pela Usiminas, eles pensaram que seria difícil o filho mudar seu jeito de ser. Entretanto, sem que ninguém da família dissesse nada, após contratado, o filho chegou a casa com o uniforme e o cabelo cortado e literalmente mudou seu comportamento - possivelmente, ao ser admitido, recebeu as devidas instruções na Usiminas. Quando aceitou o desafio de trabalhar na empresa, estava ciente dos compromissos, das exigências, responsabilidades e expectativas sociais que recaíam sobre ele. Vestir o uniforme da Usiminas levou a uma mudança de comportamento, marcando o abandono de sua antiga aparência e modo de vida boêmia para se tornar um "Homem-Usiminas"19.
17. Um exemplo interessante quanto a mudanças de comportamento provocadas pelo uniforme aconteceu em escolas públicas dos Estados Unidos. Aí, na década de 1990 , foram adotados uniformes para resolver problemas de indisciplina, roubo e uso de drogas, e os resultados foram considerados muito positivos pela comunidade escolar; ver Russell Eppinger (2009); Josh B. McDaniel (1996) e Inés Dussel (2005).

18. Ver Marcel Mauss (2003).

19. Cf. Maria Isabel de J. Chrysostomo (2009, p. 124). 
20. Cf. Jennifer Craik (2003, p. 7).
Na visão de Jennifer Craik, o uniforme funciona como um instrumento ideológico para moldar ações - físicas e mentais - e introduzir novos hábitos e postura. Endossando essa assertiva, Ana Gabriela, estudante do Ensino Médio de uma escola pública de lpatinga, comentou que o uniforme cinza da Usiminas é sinônimo de respeito entre os cidadãos de lpatinga, pois leva o trabalhador a ser percebido como alguém que honra seus compromissos e é comprometido com o sistema de operação da empresa. "Assim, no dia a dia, automaticamente essa competência é transferida à vida social desse operário, indicando que está tudo certo, bonito, com muito profissionalismo e responsabilidade." 20

Ao mencionar a importância para os jovens em serem vistos com o uniforme da Usiminas, Wallace Fidelis, estudante do Ensino Médio, escola pública, destaca que o trabalhador "pode ser admirado e ganhar um valor a mais e pode servir como exemplo para outros, por seguir um caminho adequado". Essa assertiva foi confirmada por Cléber, assistente industrial da Usiminas, 38 anos, que entrou para o Senai com 16 anos e, nessa ocasião, ingressou na Usiminas como aprendiz. Quando perguntei como ele se sentia diante de seus colegas, usando o uniforme da Usiminas, ele respondeu:

Sentia-me o máximo, pois esse era o sonho de todo garoto É semelhante a você usar o uniforme do seu time preferido, né? Era um status. Você tinha 16 anos e se sentia como um adulto, com postura de adulto. Entre meus colegas não tem nenhum marginal, mas são pessoas instáveis na vida familiar. A Usiminas me ajudou muito na formação do meu caráter. Diante daquela fase de rebeldia, de buscar o caminho errado, entrar na empresa era uma porta para o caminho certo. Então quando eu usei o meu uniforme pela primeira vez, eu pensei: Estou no caminho certo, no emprego certo! Além de conforto e segurança, o uniforme funciona na região como uma identidade de bons antecedentes.

Dados semelhantes aos que foram coletados na Usiminas em Ipatinga são apresentados por Daniel Pardini e coautores, onde demonstram a relevância da qual o uniforme se revestia na Companhia Siderúrgica Paulista (Cosipa), localizada em Cubatão-SP. Em suas análises, os autores demonstram que o uniforme compunha um sistema distintivo que simbolizava dignidade e proporcionava credibilidade no comércio de Cubatão e Santos. Assim, os trabalhadores tinham orgulho de sair uniformizados para sinalizar o pertencimento à empresa que trouxera prosperidade para a região.

Entretanto, em meados da década de 1980, a Cosipa passou por um grave período de instabilidade e desestabilização administrativa, que exigiu a intervenção do governo federal em 1988. A debilidade da situação refletiu-se no ambiente de trabalho, principalmente entre os operários, pois em sua política de contenção de gastos, a empresa suprimiu as verbas para a renovação do uniforme, que funcionava como equipamento de proteção individual.

Nos depoimentos concedidos a Pardini, Gonçalves e Kilimnik, os trabalhadores, principalmente os operários, mencionaram a dificuldade pelas quais passaram quando a empresa deixou de fornecer uniformes. Aqueles que trabalhavam na manutenção e lidavam com graxa ficaram esfarrapados, parecendo mendigos, o que afetava o orgulho de trabalhar na empresa. 
Os depoimentos demonstram o quanto os significados expressos no uniforme são importantes na constituição da identidade do trabalhador, refletindo-se em sua autoestima, especialmente entre os operários de menor poder aquisitivo. Afinal, sem o uniforme, há uma diversificação desfavorável do visual, que contrasta aqueles que podem ir para o trabalho bem vestidos e os que chegam a usar roupas surradas. $\bigcirc$ que demonstra o quanto o uniforme é depositário de valores e expectativas.

Com a compra da Cosipa pela Usiminas, em 1993, foi firmado um contrato de assistência técnica entre essas empresas, iniciando diversos encontros entre os membros de ambas as organizações. Entretanto, essa situação de proximidade entre as empresas, que historicamente eram concorrentes, gerou um mal-estar, pois os funcionários da Usiminas usavam seus uniformes quando estavam no recinto da empresa paulista. Assim, os trabalhadores da Cosipa manifestavam hostilidade à presença dos funcionários da outra empresa. Até mesmo os gerentes da siderúrgica mineira tiveram dificuldades em usar seus uniformes quando estavam na Cosipa: "O fato de ele enxergar o meu uniforme e olhar para mim e falar: 'Esse cara é da Usiminas, esse cara é aquele que comprou, esse cara é aquele que se acha o melhor'"21.

Diante desse impasse, para evitar conflitos, a solução encontrada pelos dirigentes da Usiminas foi deixar o uniforme da Usiminas e vestir o uniforme da Cosipa quando estivessem nesta empresa. Assim, o uso do uniforme favoreceu o diálogo entre as siderúrgicas, possibilitando o alcance dos resultados corporativos.

Para ressaltar a intenção de parceria entre as empresas, no primeiro encontro com os membros da Cosipa, Rinaldo Campos, presidente da Usiminas que também assumiu a presidência da Cosipa, usou o uniforme da siderúrgica paulista e enfatizou o orgulho de usá-lo, demonstrando sua intenção em resgatar a identidade e a dignidade dos trabalhadores. Visando a ressaltar o clima de paz que propunha, Rinaldo disse que iria fornecer uniforme para os trabalhadores e devolver o orgulho de vesti-lo, como também passou a usar o uniforme da Cosipa toda vez que estava na siderúrgica paulista.

$\bigcirc$ uso do uniforme da companhia paulista pelo presidente e diretores da Usiminas teve uma repercussão positiva para os cosipanos, facilitando o processo de integração entre as duas empresas e reduzindo as tensões. Os funcionários da Cosipa ficaram satisfeitos com a retomada do valor do uniforme em sua forma e cor originais, resgatando a dignidade, levando-os a se sentirem integrados ao Sistema Usiminas, comprovando poder ser o simbolismo presente no uniforme um fator de desagregação ou de integração, motivando a rivalidade ou a parceria.

Apesar de aproximar as duas empresas, o uso de um mesmo uniforme provocou nova ambiguidade para os funcionários da Usiminas quando estavam na Cosipa, pois tinham de usar o uniforme de uma companhia com a qual não se identificavam e na qual não se sentiam integrados. Usar a roupa de um concorrente histórico significava renunciar a uma identidade construída durante a trajetória profissional em uma organização. Um dos gerentes da Usiminas afirmou res (2008, p. 63). 
que vestir o uniforme da empresa rival era como colocar o corpo em uma alma que não é sua: "Não adianta pegar e botar o uniforme escrito Cosipa, ficar desfilando com Cosipa, e ser inteiramente corpo Usiminas, corpo e alma escrita"22.

A devolução dos uniformes originais aos cosipanos e sua revalorização representava o resgate de uma identidade empresarial. Entretanto, a restituição da dignidade aos trabalhadores da Cosipa representou ameaça à identidade dos membros da Usiminas, que tiveram de abrir mão do prestígio do seu uniforme em prol da integração entre as empresas. As contradições vividas pelos funcionários da Usiminas, bem como a hostilidade dos trabalhadores da Cosipa diante do uniforme cinza, revelam que ambos os grupos se sentiram ameaçados com a possibilidade de romper com uma identidade profissional construída durante muitos anos, o que comprova algumas ambiguidades do capitalismo e conflitos que os trabalhadores vivenciam no contexto de fusões e aquisições corporativas.

Apesar de conferir vantagens, status e dignidade aos trabalhadores, o uniforme também potencializa o controle sobre os trabalhadores, destacando aqueles que se desviam das normas empresariais.

controle camuflado pelo prestígio

Além do prestígio que confere, vestir o uniforme ao ir para a empresa e permanecer com ele após o trabalho sugere um controle sutil sobre a vida do funcionário. Tal vestimenta se torna um instrumento de internalização e decodificação de regras, conduzindo a uma conduta institucionalizada, pautada em normas e regras, ao mesmo tempo em que permite identificar o trabalhador no convívio comunitário, motivando a denúncia de qualquer irregularidade.

Devido a esse aspecto, na ocasião em que foi implantado, os trabalhadores não aceitaram o uniforme de bom grado. $O$ metalúrgico Paulo, aposentado da Usiminas, menciona que alguns trabalhadores achavam que usá-lo após o trabalho iria tirar a liberdade deles. Para equacionar esse impasse, ao invés de impor o uso do uniforme e correr o risco de ter trabalhadores insatisfeitos, os dirigentes da Usiminas fizeram um trabalho de convencimento das vantagens de tal uso, sempre afirmando respeitar a liberdade quanto isso. As estratégias de convencimento deram tão certo, que o uniforme virou roupa de passeio.

Apesar das vantagens que o uniforme proporcionava na região, ele também tinha seu ônus. Exemplo disso foi o episódio ocorrido com um trabalhador que estava assistindo a um jogo no lpatingão (estádio de futebol) e envolveu-se em uma briga. Como ele estava uniformizado, foi facilmente reconhecido por um de seus superiores que assistiu a cena. No dia seguinte, o funcionário foi chamado para uma conversa que implicou na sua demissão. Como mencionou um funcionário da Usiminas: "A Usiminas tem a sua ética. [...] Quem está lá dentro pode até errar, 
mas a Usiminas vai cobrar isso dele, dificilmente ele vai ficar. [...] $\bigcirc$ uniforme dá a entender que é gente boa, pode até não ser, mas a princípio é".

Outra forma de motivar os trabalhadores a vestir o uniforme em tempo integral, como uma "segunda pele", foi a instituição, em 1968, do prêmio Operário Padrão. Visando a ressaltar a fidelidade para com a empresa, o candidato ao prêmio precisa ter, na empresa, um tempo de serviço correspondente ou superior a dez anos. Ele não pode ter recebido nenhuma advertência ou sanção disciplinar, nem sofrido nenhum acidente de trabalho com perda de tempo nos últimos dez anos (uma forma de culpar o trabalhador pelo descuido na ocorrência do acidente). Outro quesito para a eleição do Operário Padrão é o envolvimento em ações "voluntárias" de "responsabilidade" social e ambiental. Para atender a esse fim, a Usiminas oficializou, em 2001, o Grupo de Voluntários de Ação Comunitária, que atende a entidades assistenciais, como asilos e creches. $\bigcirc$ cadastro dos voluntários possibilita à empresa ter controle da situação e, em seu marketing, usar as estatísticas. Estratégias como essa mantêm o trabalhador uniformizado, vigiado e, caso pratique irregularidades, denunciado e punido. Procurando vencer o prêmio, os trabalhadores buscam envolver-se constantemente em ações assistencialistas após o trabalho, sempre usando o uniforme para ser identificado.

prêmio Operário Padrão corresponde à conquista máxima de um operário: viaja com a esposa de avião para o litoral, com todas as despesas pagas, recebe vários prêmios, além de tornar-se conhecido, pois sua fotografia é divulgada em outdoors e jornais da região. Como menciona o trabalhador Cleber, que venceu o concurso Operário Padrão em seu setor de trabalho:

[Vencer o concurso] significa o reconhecimento por aquilo que você faz. Demonstra que aquilo que você está fazendo está sendo visto, está sendo avaliado e recompensado. Sentimo-nos recompensados pela nossa dedicação. Em muitas empresas a pessoa dedica, dedica, dedica e ninguém vê. Mas na Usiminas acontece o contrário. $\bigcirc$ operário padrão é um exemplo de profissionalismo que aborda não só a parte interna da empresa, mas também a parte externa, na comunidade. Tem esse fator, tudo o que você faz está sendo visto, está sendo avaliado e recompensado, na medida do possível.

Outro recurso utilizado pela Usiminas para a moldagem do trabalhador apolítico, "dócil" e "útil", nos termos de Foucault (1996) foi a implantação dos Arapongas da Usiminas, que se iniciou no período militar e perdurou até recentemente. Esse grupo era composto por espiões contratados pela empresa para bisbilhotar e controlar não só a vida dos trabalhadores, mas de qualquer pessoa que pudesse representar alguma ameaça para ela. Qualquer trabalhador que, dentro ou fora da fábrica, tivesse conduta contrária à moralidade imposta pela Usiminas tinha seu nome inserido no arquivo secreto da empresa - uma lista composta por quatro mil nomes, que continha mexericos sobre vida conjugal, traições, movimento sindical etc. A pessoa cujo nome constasse na lista era demitida e interdita a entrada de seus familiares, na Usiminas e nas demais siderúrgicas da região ${ }^{23}$.
23. Além de ter sido mencionada por diversos informantes, a existência dos Arapongas da Usiminas foi confirmada, em épocas diferentes, por reportagens em periódicos de alta circulação; ver André Vieira (1998); e Malu Gaspar (2009). 
24. Ver Guia Vale do Aço (2008).

25. Os depoimentos quanto ao orgulho do uniforme foram colhidos antes da crise de 2008 e suas consequentes demissões. Devido às exigências de tempo para encerrar a pesquisa, não foi possível voltar aos informantes iniciais para verificar a percepção deles quanto às mudanças.

26. Os depoimentos foram dados por escrito em março de 2009, ocasião em que, devido à crise mundial, houve diversas demissões na Usiminas.
Além de ser um instrumento de prestígio que possibilitava o controle sobre os trabalhadores, o uniforme da Usiminas também envolvia outros conflitos, principalmente em relação aos que não estavam inseridos na empresa.

Mudanças na percepção quanto ao uniforme: do prestígio à discriminação

O ano de 2008 marcou a saída de Rinaldo Campos Soares da presidência da Usiminas, cargo que ocupou por dezoito anos. Em 29 de abril, data do aniversário de Ipatinga, Marco Antônio Soares da Cunha Castello Branco assumiu a presidência da empresa e implantou diversas mudanças administrativas, mudando, inclusive, a logomarca e os uniformes. $\bigcirc$ novo presidente também afirmou seu propósito de romper com o amplo histórico de controle social, especialmente fora dos portões da Usiminas. E ressaltou querer participar da formação de cidadãos capazes de questionar os rumos do país. "Não queremos que as pessoas fiquem sempre achando que alguém vai tomar conta da vida delas para o resto da vida" 24 .

Com a mudança na presidência da Usiminas em 2008, o presidente Castello Branco abandonou as práticas paternalistas dos presidentes anteriores. Além disso, no mesmo ano, a crise econômica mundial abalou muito a empresa, implicando diversas demissões. Tais mudanças contribuíram para uma redução do simbolismo do uniforme na comunidade local ${ }^{25}$.

Ao analisar depoimentos de estudantes do Ensino Médio de uma escola pública de lpatinga, localizada no Bairro ldeal ( $3^{\circ}$ ano), ${ }^{26}$ e de uma escola particular (Instituto Educacional Mayrink Vieira), localizada no Bairro Cariru (1 1 o ano), e confrontá-los com os dos trabalhadores e dos moradores, notei que, embora o uniforme tenha permanecido por mais de três décadas, seu significado foi alterado ao longo das gerações.

Tendo em vista os benefícios que proporciona aos trabalhadores, os alunos da escola pública ressaltaram o interesse em trabalhar na Usiminas e vestir o uniforme da siderúrgica, que para eles ainda significa status e poder. Como menciona Jean Carlos Silva: "o uniforme representa um poderio inigualável aqui em Ipatinga. Jovens, crianças e adultos sonham em usar esse uniforme, pois aqui ele demonstra muito respeito, assim como a farda policial. [...] Quando você está usando-o, todos olham para você com mais respeito e amor".

Outro aspecto mencionado por estudantes da escola pública cujos familiares trabalhavam na Usiminas foi a política da empresa, que opta por contratar familiares, o que contribui para que o uniforme seja visto como uma tradição familiar. Marina, uma das estudantes, afirma que "muitos jovens continuam contando a trajetória da família na empresa através das gerações que se orgulham de vestir o uniforme da Usiminas". Jean Carlos reitera essa opinião: "Só de pensar que meus antepassados já usaram o uniforme, é um motivo de muita alegria. [...] vou lutar para que um dia eu também o use, pois ele é um símbolo de vitória". 
Já os estudantes da escola pública cujos familiares não trabalhavam na Usiminas evidenciam o conflito que o uso do uniforme traz na região e reclamam que, enquanto os trabalhadores uniformizados são exaltados, aqueles que não trabalhavam na empresa são muitas vezes discriminados e tratados com indiferença, levando-os a sentir-se excluídos e até mesmo alijados do exercício da cidadania. Alguns alunos, como Rosângela, denunciaram discriminação na transmissão de vínculos trabalhistas: "Se tiver duas jovens acompanhadas de seus pais à procura de emprego e um dos pais estiver com o uniforme da Usiminas e o outro não, para qual das garotas eles vão dar o serviço? Com certeza será para a garota cujo pai está uniformizado".

Diante dessa situação, o estudante Douglas Miranda critica o fato de os trabalhadores "desfilarem por toda a região, mesmo fora do expediente, demonstrando suas falsas autoridades através de seus uniformes." Endossando essa assertiva, Mayone comenta que, tempos atrás, quando os lojistas perguntavam se o consumidor ou seus familiares trabalhavam na Usiminas, aqueles que trabalhavam tinham prioridade no atendimento, "caso não trabalhasse, a pessoa era olhada de forma preconceituosa. [...] Parece que os outros que não trabalham lá são pobres e não têm condições de pagar. [...] Espero que um dia isso acabe, pois ele atrapalha muito. Não que o uniforme seja culpado, e sim as pessoas, pois olhamos a aparência, vivemos de aparência".

Para Gleiciane Souza, "o uniforme é uma forma enviesada de se perceber o outro e de marcar a sociedade materialista, manipulada por interesses, na qual a aparência fica sempre em primeiro lugar". Ela lamenta o fato de "a aparência se manifestar como forma de desrespeito às diferenças. Já não existe entre as pessoas a solidariedade, e sim mais uma forma de preconceito que desconsidera aquilo de bom que as pessoas carregam dentro de si". A forma como os trabalhadores da Usiminas são tratados contribui para que "aqueles que ganham dinheiro honestamente [mas não trabalham na empresa], muitas vezes sejam vistos como grandes otários, que não merecem que ninguém perca seu tempo com eles".

Mesmo entre alunos da escola pública, o contato com outras cidades e a ampliação do capital cultural contribuem para a redução da valorização do uniforme da Usiminas. Cíntia Araújo, por exemplo, acredita que as expectativas quanto ao uniforme são uma ilusão: "Eles pensam que a empresa é tudo, mas estão enganados. [...] Quando você conhece o mundo lá fora, você vê que a Usiminas é uma empresa qualquer. A Usiminas não é um sonho como eles falam. Encontramos empresas bem melhores e, claro, o povo não vai te tratar diferente por causa do uniforme". Comparando lpatinga com a capital mineira, ela defende que "em Belo Horizonte ninguém desfila de uniforme, porque eles acham vergonhoso. O uniforme não faz diferença igual é aqui".

Silvéria Pires menciona que "as pessoas acabaram entendendo que a Usiminas é uma empresa como as outras e que para ser reconhecido não precisa estar usando o uniforme da Usiminas". Dessa forma, "desfilar por aí com o uniforme da Usina não é mais nada além de uma prova de que se está trabalhando", destaca Aline Otero. Na visão de Mariana Anício: "Os funcionários estão 
trabalhando por trabalhar, sem prazer e querendo chegar rapidamente em casa para se livrar do terrível uniforme". Jaqueline Emanuela argumenta que o uniforme "tem sido usado com vergonha por muitos que deram a vida pela empresa. $\bigcirc$ que era sinal de estabilidade, não se sabe até quando o emprego será preservado. O que era sinal de poder tem sido sinal de fracasso". Diante da perda do seu prestígio inicial, Priscila Mara conclui: "Se pensarmos que o uniforme é um cartão de visita, com certeza esse cartão já passou da validade".

Com a perda do simbolismo inicial, Bruna Carvalho menciona que o uniforme passou a indicar apenas padronização e disciplina. "O uso de uniforme evita tirar a atenção dos colegas, bem como o exagero em decotes, roupas curtas e cores muito vibrantes que são desapropriadas para um ambiente de seriedade e respeito."

Entre os estudantes do ensino particular, nenhum deles demonstrou vontade de seguir o exemplo de seus avós e pais que fizeram carreira na Usiminas. Ao contrário, revelaram interesse em frequentar um curso universitário e fazer carreira em outra cidade, atuando em uma profissão que proporcione maior status, como medicina, odontologia, engenharia, direito e psicologia. Aline Otero acredita que "as famílias desejam muito mais para seus parentes do que uma simples vaga na Usiminas. Hoje, a ideia é preparar os jovens para algo maior, para profissões mais respeitadas e, na maioria das vezes, mais bem remuneradas". Eila Dutra afirma que "os pais esperam que, caso seus filhos venham trabalhar na Usiminas, ao menos ocupem um cargo mais elevado".

Além de não almejarem trabalhar na Usiminas, é comum alunos da escola particular desprezarem o uso do uniforme da empresa, referindo-se aos trabalhadores como "peão da Usiminas", por realizar trabalho braçal e de baixo status. Na visão de Diego Santos, "o uniforme pode ser visto como sinal de status ou como roupa de 'peão', nome dado aos empregados de baixo cargo e com remuneração baixa". André Guimarães menciona que "quando passa um trabalhador com o uniforme as pessoas pensam: "lá vai o peão da Usina'".

Com as mudanças implantadas pela empresa em maio de 2009, Paulo Roberto de Souza, historiador e ex-trabalhador da Usiminas, informou-me que a nova diretora de recursos humanos, Denise Brum, passou a desestimular "o uso do uniforme como indumentária do cotidiano dos empregados. Ela alerta que o uniforme foi criado para ser usado na fábrica. Parece-me que há uma tendência em desmontar o 'mito do uniforme'". $\bigcirc$ estudante Rubens Júnior acredita que a mudança no uniforme se deve à perda do status e poder do uniforme da Usiminas. O intuito é "renovar o grande desejo das pessoas de vestir o uniforme e trazer uma nova cara para a empresa, que está de presidente novo e pretende renovar seu estilo de poder".

Para efetivar a mudança, a empresa apresentou aos trabalhadores duas opções de cores para os novos uniformes: azul marinho ou grafite, que na verdade é um novo nome para o cinza, que se torna mais escuro. Na votação que aconteceu nos dias 25 a 27 de maio de 2009, os trabalhadores optaram pela cor grafite. Embora o uniforme azul pudesse ter sido escolhido pela associação ao glamour do uniforme de aeromoças e pilotos, os funcionários 
preferiram continuar vestindo o cinza (agora denominado grafite) que tradicionalmente os vem identificando com a siderurgia ipatinguense. Essa eleição se deu, principalmente, porque dentro da área da Usiminas existem empreiteiras cujo uniforme é azul. Manter o cinza significa diferenciar a Usiminas das empreiteiras, além de ser a cor dos uniformes que trouxeram, por tantos anos, prestígio para os trabalhadores, mesmo que ocultasse o controle.

Com a mudança no uniforme, os novos modelos foram diversificados por setor: administrativo (masculino e feminino) e operacional. De acordo com a nova política, todas as empresas do Grupo Usiminas passarão a usar o mesmo uniforme com sua logomarca. Uma investigação sobre a receptividade dos uniformes da Usiminas pelos trabalhadores da Cosipa, que tiveram que se despir do velho uniforme cáqui - que thes trouxe dignidade - para vestir o cinza da sua concorrente histórica, parece instigante.

Conclusão: A vida social do uniforme e suas memórias

Quando a Usiminas foi construída, a contratação de milhares de operários analfabetos e semianalfabetos, comandados pelos engenheiros, ocasionou uma hierarquização das funções e cargos, além da formação de uma elite industrial de engenheiros. Os privilégios e as diferenças entre as classes provocaram muitos embates. Assim, a adoção de um mesmo uniforme por todos e a demonstração da valorização dos trabalhadores visavam a "neutralizar" as desigualdades, ou melhor, camuflar e equilibrar as tensões entre as classes.

Isso tornou-se possível porque o uniforme é também um mecanismo que favorece a disciplina, a ordem e o controle na fábrica, potencializando a vigilância, possibilitando que todos reconheçam os funcionários da Usiminas e denunciem qualquer irregularidade. Afinal, caso o discurso da vigilância e do controle fosse dito abertamente, poderia ocasionar revoltas. Assim, a Usiminas aproveitou de sua grandiosidade e de seu poder de influência para, paralelamente aos mecanismos de controle, instituir o discurso do orgulho de se trabalhar na empresa e de usar seu uniforme. Para que esse discurso atingisse o efeito desejado, o exemplo do orgulho passou a ser dado por aqueles que ocuparam os altos escalões, a começar pelo presidente, que ia a toda parte usando seu honroso uniforme.

Dessa forma, a história da Usiminas revela que o uniforme corporifica um misto de orgulho e medo, de bônus e ônus. Vestir o uniforme é corporificar acordos e lembrar a todo instante os compromissos assumidos com a empresa. Essa vestimenta oferece aos usuários o bônus de desfrutar de privilégios, especialmente ao se compararem aos trabalhadores das empresas terceirizadas, - que implica segurança e status. $\bigcirc$ grande ônus que traz para o trabalhador é ter sua vida controlada e sua espontaneidade podada, o que pode implicar insegurança, medo e até revolta. 
Quanto ao fardo que o uso do uniforme pode representar, um exemplo interessante foi relatado por uma professora universitária que trabalha comigo. Quando contei a ela a história da Usiminas e os mecanismos de controle camuflados pelo orgulho, ela me disse: "Agora que você está me contando isso é que estou entendendo o meu irmão!" Ela comentou que seu irmão se formou em Engenharia Eletrônica e foi contratado pela Usiminas, onde atuou no período de 1982 a 1984. Ele tinha um bom salário e boas perspectivas para ter uma carreira promissora na empresa. Inclusive, estava se preparando para ir ao Japão, se aperfeiçoar profissionalmente. Em um determinado dia, ele largou tudo, voltou para a casa dos pais e nunca mais procurou emprego. Tornou-se uma pessoa estranha por não ter se realizado profissionalmente. Ela disse que, quando a família perguntava por que ele havia abandonado o emprego, ele não dava explicações, apenas dizia que "o pessoal de lá é muito controlador. Eles ficam sabendo de tudo o que a gente faz, com quem saiu e até quantas cervejas tomou". A experiência frustrante desse engenheiro nos leva a inferir que ele se sentiu profundamente incomodado em vestir o uniforme da Usiminas e perder sua liberdade pessoal em prol de uma identidade profissional, que ele não estava disposto a assumir, vivida fora dos portões da fábrica. Assim, ele tirou definitivamente o uniforme da empresa, mas isso atrapalhou a retomada de sua vida profissional.

Considerando os diversos mecanismos a que a Usiminas recorre para manter o simbolismo do uniforme, podemos concordar com Geertz (1989) que a cultura é formada por uma rede de significados que se conectam para formar o tecido social. Assim, a missão do antropólogo seria desvendar esses significados, estabelecendo relações entre informantes, textos, objetos, normas, símbolos e tudo - que favoreça uma descrição minuciosa que possibilite maior inteligibilidade de uma realidade.

Diante da trama social apresentada, procurei dar visibilidade às múltiplas faces a que o uniforme da Usiminas se liga, além de demonstrar que, mais do que um objeto material inerte, ele tem uma vida social muito dinâmica. Como elemento da cultura material, não pode ser visto apenas como o somatório de alguns pedaços de pano, aviamentos e costuras produzidos pela lógica industrial e capitalista. Conforme lembra Appadurai (1995), os artefatos têm vida, alma e memória. $\bigcirc$ uniforme da Usiminas traz a história de vida de milhares de trabalhadores que se dedicaram em prol de uma causa, o que nos leva a confirmar - quanto as roupas comportam rico potencial de análise, por serem objetos centrais à experiência humana, revestirem o corpo, acompanharem a trajetória profissional, e participarem de momentos tristes e felizes, de tensão e emoção. Isso torna o uniforme muito significativo, atuando como uma espécie de "segunda pele". Porém, não uma pele fixa, mas em contínua mutação, que abriga uma diversidade de sensações e sentimentos, acumulando experiências e carregando traços de uma memória individual e coletiva. Devido à alta proximidade com o usuário, o vestuário incorpora valores e simbolismos. Por isso, é um elemento propício para revelar as tramas e nuances do mundo social. 


\section{REFERÊNCIAS}

ALMEIDA, Adilson J. de. Uniforme da guarda nacional 1831-1852: a indumentária na organização e funcionamento de uma associação armada. 1998. Dissertação (Mestrado em História Social) - Faculdade de Filosofia, Letras e Ciências Humanas de Universidade de São Paulo, São Paulo, 1999.

APPADURAI, Arjun (Org.). The social life of things: commodities in cultural perspective. New York: Cambridge University Press, 1986.

BOURDIEU, Pierre; DELSAUT, Yvette. O costureiro e sua grife. In: BOURDIEU, Pierre. A produção da crença. Porto Alegre: Zouk, 2006.

BOSI, Ecléia. Memória e sociedade: lembranças de velhos. São Paulo: Companhia das Letras, 1994.

CHRYSOSTOMO, Maria Isabel de J. Um projeto de cidade-indústria no Brasil moderno: o caso de Ipatinga (1950-1964). Cronos, Natal, v. 9, p. 109-134, 2009.

CRAIK, Jennifer. A política cultural do uniforme. Fashion Theory, Londres, v. 7, n. 2, p. 127-147, jun. 2003

DUSSEL, Inés. Cuando las apariencias no engañan: uma historia comparada de los uniformes escolares en Argentina y Estados Unidos (siglos XIX-XX). Pro-Posições, Campinas, v. 16, n. 1, p. $65-86$, jan.-abr. 2005.

EPPINGER, Russell. E. School uniforms: Does what students wear really make a difference? 2009. Disponível em <http://www.newfoundations.com/PracEthics/Eppinger.html>.

FARIAS, Rita de Cássia P. Entre a igualdade e a distinção: a trama social de uma grande empresa corporificada no uniforme de trabalho. 2010. 329f. Tese (Doutorado em Antropologia Social) Instituto de Filosofia, Letras e Ciências Humanas da Universidade de Campinas, Campinas, 2010.

GASPAR, Malu. Está ruim... e pode piorar. Exame, Rio de Janeiro, 2 fev. 2009.

GEERTZ, Clifford. A interpretação das culturas. Rio de Janeiro: LTC, 1989.

GUIA VALE DO AÇO. Usiminas: mudanças em andamento. 12 set. 2008. Disponível em: <http:// www.guiavaledoaco.com.br/2008/informativo.php?id_noticia=924\&caderno=Cidades $>$.

MAUSS, Marcel. Uma categoria do espírito humano: a noção de pessoa, a noção do eu. In: Sociologia e Antropologia. São Paulo: Cosac Naify, 2003. p. 367-397.

MCDANIEL, Josh B. Can uniforms save our schools? Reader's Digest Magazine. September 1996, p. 78-82.

MOREIRA, Regina da L. CSN, um sonbo feito de aço e ousadia. Rio de Janeiro: CPDOC: Fundação CSN, 2005.

PARDINI, Daniel; GONÇALVES, Carlos A.; KILIMNIK, Zélia M. Manifestações simbólicas nas relações intra e interorganizacionais. $E$ \& G Economia e Gestão, Belo Horizonte, v. 8, n. 17, p. 51-69, 2008. 
STALLYBRASS, Peter. O casaco de Marx: roupas, memória, dor. Belo Horizonte: Autêntica, 2004

SOUZA, Paulo R. de. Cultura, trabalbo e conflitos em Ipatinga nos anos 60. 2007. Dissertação (Mestrado em História) - Departamento de História da Universidade Federal de Uberlândia, Uberlândia, 2007.

TULER, Marilene A. R. O massacre de Ipatinga: mitos e verdade. Belo Horizonte: O Lutador, 2007.

USIMINAS Jornal. Encarte especial, maio 2004.

USIMINAS. Usiminas conta a sua bistória. Belo Horizonte: Usiminas, 1987.

VIEIRA, André. Arapongas da Usiminas. Istoé, São Paulo, 29 abr. 1998.

Artigo apresentado em 5/2010. Aprovado em 10/2010. 